\title{
323 - I'd prefer to stay at home but I don't have a choice': Irish social workers' experiences of decision-making in care planning with older people with dementia
}

John P. Brennan

This paper is based on a collaborative research study undertaken by the Irish Association of Social Workers, Age Action Ireland, The Alzheimer Society of Ireland and the School of Social policy, Social Work and Social Justice, University College Dublin. The study explored the experiences and views of social workers working with older people, including people with dementia. The purpose of the study was to investigate how the health and social care system in Ireland was responding to the care needs, required supports and preferences of older people. This paper will mainly focus on reported experiences related to older people with dementia in decision-making about their care.

Data collection included a mixed method approach, that is, (i) an on-line survey of social workers across Ireland reporting on their open caseload over a period of one month $(\mathrm{N}=38)$ ) and (ii) semi-structured telephone interviews with social workers $(\mathrm{N}=21)$.

The Quantitative data was analysed using SPSS statistical software to produce descriptive and bivariate results. For the qualitative data an iterative data reduction process was used.

Findings echoed that of other Irish research demonstrating (i) that the preference of older people is to remain living at home and receiving care in this setting as needed, and (ii) that this preference is not being realized. The study further highlighted variations in participation levels of people with dementia in the decision-making process, the barriers to participation and the place of family relationships in the decision-making process. The study made recommendations as to how to address these issues. The findings will also be considered within the context of social justice for older people. 